\title{
Characterization of organic compounds from biosolids of Buenos Aires city
}

\author{
S.I.Torri ${ }^{1 *}$ and C. Alberti ${ }^{2}$ \\ ${ }^{1}$ Cátedra de Química General e Inorgánica, Facultad de Agronomía, Universidad de Buenos. Aires. Av.

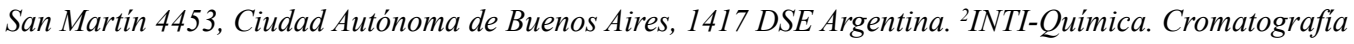 \\ gaseosa y Espectrometría de Masas. Avenida Gral Paz 5445, San Martín, Buenos Aires, B1650 WAB \\ Argentina. ${ }^{*}$ Corresponding author: torri@agro.uba.ar
}

\begin{abstract}
Summary
The use of biosolids as a source of organic matter improves the physical and chemical properties of agricultural soils, resulting in an increase in crop yields. In previous studies, between $29-45 \%$ of sludge-borne carbon was recalcitrant a year after land application of biosolids from Buenos Aires City. Although high concentrations of some persistent organic pollutants have been worldwide reported to be present in this waste, this study has not been addressed in Argentina until now. Therefore, our aim was to characterize the organic compounds in Buenos Aires City's biosolids. Different extracting solvents were evaluated for ultrasound-assisted extraction (UAE). Results indicated that the combination of hexane: acetone $(3: 2, \mathrm{v} / \mathrm{v})$ showed the highest extractability, allowing the identification of a wide range of organic compounds, without a clean-up or a pre-concentration step. The organic compounds mainly consisted of fatty acids, n-alkanes and steroids, with concentrations of persistent organic pollutants below detection limits. We conclude that the recalcitrant organic fraction reported in previous research is mainly due to the presence of stable sterols.
\end{abstract}

Keywords: biosolids, organic compounds, ultrasound-assisted extraction, sterols, fatty acids 


\section{Introduction}

About 1,800,000 metric tons of biosolids is annually produced in Buenos Aires City, Argentina. The accumulation of this waste poses a growing environmental problem. Worldwide, the disposal of biosolids includes land application, composting, landfilling or incineration. Biosolids represent an easily accessible source of organic matter and nutrients. Therefore, recycling biosolids to agricultural land is regarded as the most pragmatic and environmentally sustainable approach by most scientific and regulatory authorities. In previous studies, Torri et al. (2003) reported that between $29-45 \%$ of biosolids-borne carbon was recalcitrant, and remained in three representative soils of the Pampas Region, Argentina, a year after its land application. The range of persistent organic pollutants reported to be present in biosolids is extensive and diverse, and may include polychlorinated biphenyls (PCBs), polycyclic aliphatic hydrocarbons (PAHs), phthalic acid esters (PAEs) and surfactants such as linear alkylbenzene sulfonate (Passuello et al., 2010). These pollutants are sorbed onto sludge-organic matter owing to their lipophilic and hydrophobic properties (Harrison et al., 2006). Contrary to most organic compounds present in other organic amendments, these compounds exhibit a high environmental persistence, mainly due to their chemical stability, relatively low volatility and high dielectric constant. Moreover, 16 PAHs and 6 phthalic acid esters (PAEs) compounds have been identified as priority pollutants by the United States Environmental Protection Agencies (USEPA) because of their toxic, mutagenic and/or carcinogenic properties. Upon soil incorporation, these pollutants are transferred to the soil matrix, with possible adverse effects both for the environment and for humans.

The identification of biosolids organic compounds is usually performed by gas chromatography (GC) with mass spectrometric detection (MS). An extrac- tion step is generally required in solid matrices prior to analysis. Several analytical methods have been described to extract organic contaminants from soil, biosolids, or soil-biosolids matrices. Conventional sample extraction procedures like Soxhlet are time consuming and usually hazardous to health due to the high volume of potentially toxic solvents used. For these reasons, faster, less solvent consuming and more automated techniques have replaced conventional extractions. Compared to most modern extraction methods, ultrasound-assisted solvent extraction (UASE) requires no specialized laboratory equipment. The main advantages of this extraction method include reduced extraction time and reduced solvent consumption (Albaseer et al, 2010). This extraction technique has been reported to be a good alternative for the extraction of organic compound from sludge matrices (Santos et al., 2007).

Although biosolids are not commonly applied to soils in Argentina, it is expected that, as in the rest of the world, this practice will be adopted as a main disposal route in a near future. For its safe application in forest, agricultural or degraded soils it is necessary to discard the existence of persistent organic pollutants in its stable organic pool. However, to our knowledge, no studies have been performed on the characterization of the organic matter of Buenos Aires City's biosolids. Moreover, due to the large amounts of sewage sludge generated daily, there will be the necessity of a rapid and economic method for the routine determination of potentially toxic organic compounds present in this organic waste to manage their release into the environment.

The objective of the present study was to characterize the organic compounds present in Buenos Aires City's biosolids in order to identify the composition of the recalcitrant organic fraction. 


\section{Materials and methods}

\subsection{Sampling}

Biosolids from $\mathrm{N}$ outskirts of Buenos Aires City was provided by the local water operator Agua y Saneamientos Argentinos S.A. (AySA). The aerobically stabilized biosolids was dried in holding pools in the sewage sludge treatment plant. Biosolid samples were collected in triplicate in four campaigns (one per season) along a year, and were supposed to be a composite sample over the sampled period. Before analysis, samples were oven dried at $40{ }^{\circ} \mathrm{C}$ to stable mass, grounded into a fine powder $(<2 \mathrm{~mm})$, bottled in a polypropylene box and stored in the dark at room temperature until analysis.

\subsection{Ultrasound-assisted extraction procedure}

At the beginning of the experiment, the extraction efficiency of toluene, n-hexane, toluene: methanol $(10: 1, \mathrm{~V} / \mathrm{V})$, methylene chloride and hexane: acetone $(3: 2, v / v)$ was compared. Analytical grade n-hexane, toluene, dichloromethane, methanol and acetone were purchased from Merck Co. Ten $g$ of biosolids sample was sonicated $20 \mathrm{~min}$ with $20 \mathrm{ml}$ of solvents in an ultrasonic bath (frequency $35 \mathrm{kHz}$, Neytech $28 \mathrm{H}$, USA). The extracts were filtered by using Whatman filter paper and were reduced to $1 \mathrm{~mL}$ with rotary evaporator at $40{ }^{\circ} \mathrm{C}$ and injected into the GC-MS system.

Optimum volume of solvent, optimum sonication time and optimum repetition of extraction were afterwards determined. These optimization experiments were carried out by using biosolids spiked samples. For that, biosolids samples were spiked with 20 $\mathrm{mg} \mathrm{kg}{ }^{-1}$ of di-(2-ethyl-hexyl) phthalate, palmitic acid and phenanthrene for extraction optimization. The spiking solutions were prepared by dissolving analytes in a minimal volume of acetone. Solutions were sprayed onto dry biosolids samples with thorough mixing. The spiked samples were placed under a fume hood and mixed regularly for 10 days to evaporate the carrier solvent. In order to determine the optimum volume of solvent, $5 \mathrm{~g}$ of spiked biosolids sample was sonicated for 20 min with 5, 10 and $15 \mathrm{ml}$ of hexane: acetone (3:2, $\mathrm{v} / \mathrm{v}$ ). The optimum sonication time was determined by sonicating $5 \mathrm{~g}$ of spiked biosolids sample with $10 \mathrm{ml}$ of hexane: acetone $(3: 2, \mathrm{v} / \mathrm{v})$ for $10,15,20,25$ and $30 \mathrm{~min}$ at room temperature. The samples were centrifuged at $3200 \mathrm{rpm}$ for $20 \mathrm{~min}$ and the liquid phase was injected into the GC-MS system. The extraction procedure was repeated another three times with the residue. The cumulative recovery was calculated by adding recoveries of compounds determined in each extract.

\subsection{Gas chromatography-mass spectrometry (GC/ MS) analysis}

Gas chromatography-mass spectrometry (GC/MS) analysis was carried out with a GCMS-QP2010 equipment from Shimadzu (Shimadzu Corporation, Japan) equipped with a DB-1 fused silica capillary column (polydimethylsiloxane, $30 \mathrm{~m}$ long x $0.25 \mathrm{~mm}$ i.d.0.25 $\mu \mathrm{m}$ film thickness, J\&W Scientific, Folson, CA). The GC system was operated in splitless mode and 1- $\mu 1$ portions of the extracts were injected by using an autosampler. Both the injection liner, which contained deactivated glasswool for splitless injection (Agilent Technologies), and the transfer line were maintained at $280{ }^{\circ} \mathrm{C}$. The oven temperature was programmed to rise from $70{ }^{\circ} \mathrm{C}$ ( 1 min hold) to $290{ }^{\circ} \mathrm{C}$ at a rate of 30 ${ }^{\circ} \mathrm{C} \min ^{-1}$ (22 min hold). Helium was used as the carrier gas at linear velocity $40 \mathrm{~cm} \mathrm{~s}^{-1}$. The electron-impact (EI) ionization energy was $70 \mathrm{eV}$. The presence of the compounds was confirmed by means of the mass spectra obtained in full scan acquisition mode in the $\mathrm{m} / \mathrm{z}$ range from 20 to 500 . High purity analytical standards ( $>98.5 \%)$ of 2-ethyl-hexanoic acid, hexadecane, 1-octadecanol, palmitic acid, eicosane, di-n-octyl 
phthalate, phenanthrene and cholesterol were used in addition to retention time and quantification ions to assure proper compound identification during quantitative analysis.

The system was controlled by an interface module and a personal computer. Mass spectra were compared with reference compounds in mass spectral libraries. The peaks of the total components were integrated to obtain the total area. The area of each compound was divided by the total area and expressed as percentage.

\section{Results and Discussion}

\subsection{Biosolids characteristics}

Selected characteristics of biosolids are presented in Table 1.

Table 1. Selected properties of biosolids.

\begin{tabular}{lc}
\hline & Biosolids \\
\hline $\mathrm{pH}$ & 5.82 \\
Moisture content $(\%)$ & 5 \\
Total organic carbon $\left(\mathrm{mg} \mathrm{g}^{-1}\right)$ & 251 \\
Total N (mg g & \\
Total P $\left(\mathrm{mg} \mathrm{g}^{-1}\right)$ & 19.3 \\
Electrical conductivity $\left(\mathrm{dS} \mathrm{m}^{-1}\right)$ & 0.052 \\
Cation exchange capacity $\left(\mathrm{cmol}_{(\mathrm{c})} \mathrm{kg}^{-1}\right)$ & 0.90 \\
Ca $\left(\mathrm{mg} \mathrm{g}^{-1}\right)$ & 11.95 \\
Mg $\left(\mathrm{mg} \mathrm{g}^{-1}\right)$ & 22.5 \\
$\mathrm{~K}\left(\mathrm{mg} \mathrm{g}^{-1}\right)$ & 5.6 \\
Total Cd $\left(\mathrm{mg} \mathrm{kg}^{-1}\right)$ & 10.7 \\
Total Cu $\left(\mathrm{mg} \mathrm{kg}^{-1}\right)$ & 10.08 \\
Total Pb $\left(\mathrm{mg} \mathrm{kg}^{-1}\right)$ & 750.8 \\
Total Zn $\left(\mathrm{mg} \mathrm{kg}^{-1}\right)$ & 334.2 \\
\hline
\end{tabular}

The content of PTE in biosolids was below the maximum permissible concentration of PTE by Argentinean regulations (Torri and Lavado, 2008 a; Torri and Lavado 2008 b).

\subsection{Optimisation of extractant conditions}

Good analytical performance (with recoveries ranging from $92-98 \%$ ) occurred when $10 \mathrm{ml}$ of n-hexane or 3:2(V/V) hexane: acetone were used to extract $5 \mathrm{~g}$ of spiked biosolids samples (three extraction cycles) for $20 \mathrm{~min}$. A lower solvent volume led to lower recoveries, probably due to a saturation of the solvent by the extracted compounds, whereas increasing solvent volume did not increase extraction efficiency. Instead, it led to more diluted extracts, and longer time was required for concentration. Recoveries increased with sonication time up to $20 \mathrm{~min}$, with few fluctuations for increasing time. Thus, the optimum sonication time for extraction was selected as $20 \mathrm{~min}$. No organic compounds were found in the liquid phase obtained after the third extraction, so the number of extraction cycles was set to three.

\subsection{Comparison of extraction solvents}

The chromatograms obtained for each extractant are shown in Figure 1. The organic compounds were identified by mass spectra (Table 2). The results herein obtained indicate that all extractants allowed a direct analysis after extraction without any clean up step. However, the type of organic compounds extracted depended on the solvent used, indicating their different ability to solubilize diverse biosolids-borne organic compounds. 


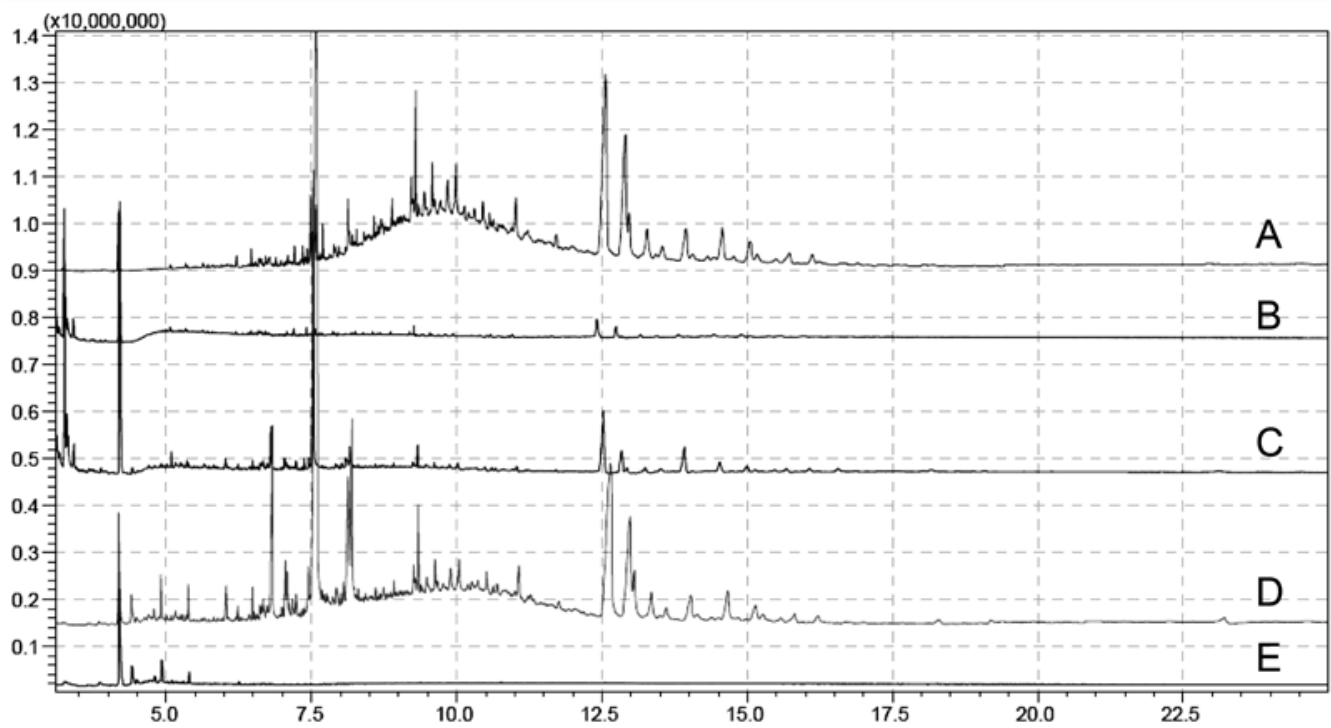

Figure 1. GC-MS total ion chromatogram of biosolids's extracts obtained by UASE with A) n-hexane, B) toluene, C) toluene: methanol $(10: 1, \mathrm{v} / \mathrm{v}), \mathrm{D})$ hexane: acetone $(3: 2, \mathrm{v} / \mathrm{v})$ and $\mathrm{E})$ dichloromethane. Identification of selected compounds are provided in Table 2.

Table 2. Retention times for selected compounds of Figure 1.

\begin{tabular}{lll}
\hline R. time & Name & formula \\
\hline 3.251 & benzene, 1,2,4-trimethyl- & $\mathrm{C}_{9} \mathrm{H}_{12}$ \\
4.196 & cyclopentasiloxane, decamethyl & $\mathrm{C}_{10} \mathrm{H}_{30} \mathrm{O}_{5} \mathrm{Si}_{5}$ \\
7.533 & Palmitic acid & $\mathrm{C}_{16} \mathrm{H}_{32} \mathrm{O}_{2}$ \\
12.66 & Cholestan-3-ol, (3.beta.,5.alpha.) & $\mathrm{C}_{27} \mathrm{H}_{48} \mathrm{O}$ \\
9.295 & Dioctyl phthalate & $\mathrm{C}_{24} \mathrm{H}_{38} \mathrm{O}_{4}$ \\
12.98 & Cholestane, 5,6-epoxy,(5.alpha.,6.alpha.) & $\mathrm{C}_{27} \mathrm{H}_{46} \mathrm{O}$ \\
13.35 & Cholestan-3-one, (5.alpha.) & $\mathrm{C}_{27} \mathrm{H}_{46} \mathrm{O}$ \\
14.03 & Dihydrocholesterol & $\mathrm{C}_{27} \mathrm{H}_{48} \mathrm{O}$ \\
14.67 & Stigmastanol & $\mathrm{C}_{29} \mathrm{H}_{52} \mathrm{O}$ \\
\hline
\end{tabular}


Although widely used, dichloromethane provided a low extraction capacity in this work (Figure 1). These results are in good agreement with those reported by Codina et al. (1994) and Manoli and Samara (1996). The chromatograms obtained in this research indicated that toluene was the least efficient extracting agent, while n-hexane or the combination of hexane: acetone $(3: 2, \mathrm{v} / \mathrm{v})$ showed the highest solubility and extractability of analytes. These results are in agreement with previous studies, which suggested that $n$-hexane is generally the preferred solvent for the extraction of PCBs or PAHs (Masih and Taneja 2006; Zhou et al., 2010). However, as $n$-hexane is more toxic than other linear alkanes (Huang 2008) it should be replaced or partially replaced by a less harmful solvent. The mixture of hexane: acetone showed a higher extraction capacity than the one obtained by single solvents, allowing the identification of a wide range of organic compounds. The higher results obtained with this binary solvent are in agreement with earlier findings (Kristenson et al., 2005; Huang et al., 2011) and may be explained by a better surface contact between solvent and biosolids due to a better wetability. Consequently, the mixture of hexane: acetone $(3: 2 \mathrm{v} / \mathrm{v})$ was selected as the extraction solvent for the identification of biosolids' organic compounds.

\subsection{Characterization of biosolids' organic compounds}

The main organic compounds identified in biosolids samples were grouped according to their chemical nature into two major classes: polar compounds and aliphatic compounds (Figure 2, Table 3).

All chromatograms showed the presence of two families of polar compounds: fatty acids and steroids. Fatty acids exhibit a short retention time (4 - $12 \mathrm{~min})$ and constitute the predominant family of compounds in the polar fraction, representing $51 \%$ of the organic compounds extracted with hexane: acetone. Table 3 indicates the predominance of even fatty acids (in the range from $\mathrm{C}_{12}$ to $\mathrm{C}_{18}$ ) with a dominance of chains containing 16 and 18 carbons. This result is typical of higher plants or animal contribution to the fatty acids composition (Rao 1990). Kitchen wastes derived from vegetable oils and animal fats show typical distributions of fatty acids dominated by $\mathrm{C}_{16: 0}$ (hexadecanoic or palmitic acid), $\mathrm{C}_{18: 0}$ (octadecanoic or stearic acid), $\mathrm{C}_{\text {18:109 }}$ (octadec-9-enoic or oleic acid) (Gibson et al, 2005) with palmitic acid being the most abundant (35.11\%, Table 2). Human fecal fatty acids are also dominated by $\mathrm{C}_{18: 1 \mathrm{w} 9}$ (oleic acid), $\mathrm{C}_{18: 0}$ (stearic acid) and $\mathrm{C}_{\text {16:0 }}$ (palmitic acid) (Quéméneur and Marty, 1994). 


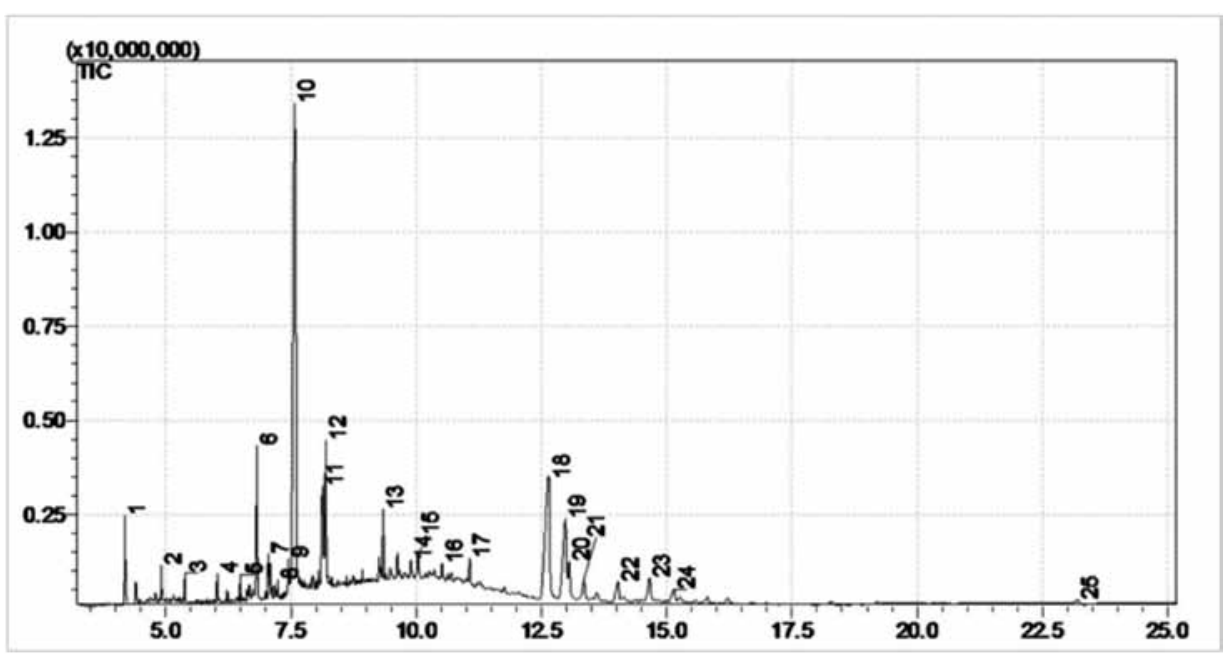

Figure 2. mean GC-MS chromatogram of biosolids' extracts obtained by UASE using hexane: acetone (3:2, v/v). Identification numbers in Table 2

Table 3. Mean average retention times in all biosolids samples for compounds of Figure 2.

\begin{tabular}{|c|c|c|c|c|}
\hline Peak & R. time & $\%$ area & Name & formula \\
\hline 1 & 4.18 & 1.94 & Cyclopentasiloxane, decamethyl- & $\mathrm{C}_{10} \mathrm{H}_{30} \mathrm{O}_{5} \mathrm{Si}_{5}$ \\
\hline 2 & 4.91 & 0.68 & Dodecane & $\mathrm{C}_{12} \mathrm{H}_{26}$ \\
\hline 3 & 5.38 & 0.32 & Tetradecane & $\mathrm{C}_{14} \mathrm{H}_{30}$ \\
\hline 4 & 6.03 & 0.45 & Dodecanoic acid & $\mathrm{C}_{12} \mathrm{H}_{24} \mathrm{O}_{2}$ \\
\hline 5 & 6.49 & 0.28 & 1-tetradecanol & $\mathrm{C}_{14} \mathrm{H}_{30} \mathrm{O}$ \\
\hline 6 & 6.83 & 4.94 & Tetradecanoic acid & $\mathrm{C}_{14} \mathrm{H}_{28} \mathrm{O}_{2}$ \\
\hline 7 & 7.05 & 1.13 & Pentadecanoic acid & $\mathrm{C}_{15} \mathrm{H}_{30} \mathrm{O}_{2}$ \\
\hline 8 & 7.24 & 0.25 & 1-octadecanol & $\mathrm{C}_{18} \mathrm{H}_{38} \mathrm{O}$ \\
\hline 9 & 7.45 & 1.09 & Dibutyl phthalate & $\mathrm{C}_{16} \mathrm{H}_{22} \mathrm{O}_{4}$ \\
\hline 10 & 7.58 & 35.11 & Palmitic acid & $\mathrm{C}_{16} \mathrm{H}_{32} \mathrm{O}_{2}$ \\
\hline 11 & 8.13 & 4.68 & Oleic acid & $\mathrm{C}_{18} \mathrm{H}_{34} \mathrm{O}_{2}$ \\
\hline 12 & 8.20 & 4.64 & Stearic acid & $\mathrm{C}_{18} \mathrm{H}_{36} \mathrm{O}_{2}$ \\
\hline 13 & 9.34 & 2.24 & Dioctyl phthalate & $\mathrm{C}_{24} \mathrm{H}_{38} \mathrm{O}_{4}$ \\
\hline 14 & 9.90 & 3.06 & Docosane & $\mathrm{C}_{22} \mathrm{H}_{46}$ \\
\hline 15 & 10.04 & 3.87 & Tretadecosane & $\mathrm{C}_{24} \mathrm{H}_{50}$ \\
\hline 16 & 10.52 & 2.6 & Octacosane & $\mathrm{C}_{28} \mathrm{H}_{58}$ \\
\hline 17 & 11.07 & 3.17 & Triacontane & $\mathrm{C}_{30} \mathrm{H}_{62}$ \\
\hline 18 & 12.66 & 13.26 & $5 \beta$-cholestan- $3 \beta$-ol & $\mathrm{C}_{27} \mathrm{H}_{48} \mathrm{O}$ \\
\hline 19 & 12.98 & 6.6 & Cholestane, 5,6-epoxy-, (5.alpha.,6.alpha)- & $\mathrm{C}_{27} \mathrm{H}_{46} \mathrm{O}$ \\
\hline 20 & 13.06 & 1.82 & 5-cholesten-3 $\beta$-ol & $\mathrm{C}_{27} \mathrm{H}_{46} \mathrm{O}$ \\
\hline 21 & 13.35 & 2.29 & Cholestan-3-one, (5.alpha)- & $\mathrm{C}_{27} \mathrm{H}_{46} \mathrm{O}$ \\
\hline 22 & 14.03 & 1.78 & Dihydrocholesterol & $\mathrm{C}_{27} \mathrm{H}_{48} \mathrm{O}$ \\
\hline 23 & 14.67 & 2.18 & Stigmastanol & $\mathrm{C}_{29} \mathrm{H}_{52} \mathrm{O}$ \\
\hline 24 & 15.14 & 1.27 & not identified & \\
\hline
\end{tabular}


Steroids presented a higher retention time than fatty acids, in accordance with their higher molecular weight. This fraction represented the $13 \%$ of the organic matter extracted with hexane: acetone. The distribution of sterols is dominated by the presence of $5 \beta$-cholestan- $3 \beta$-ol (coprostanol), in good agreement with the results reported by Jardé et al. (2005) and Takada and Eganhouse (1998). Stigmastanol, a sterol found in a variety of plant sources, was also detected. Cholestane-based sterols are commonly formed as reduction products of cholesterol (cholest-5-en-3 $\beta$-ol) in the intestinal tracts of higher mammals by anaerobic microbial hydrogenation (Walker et al., 1982).

Aliphatic compounds represented approximately $14 \%$ of the organic matter present in biosolids samples. The analysis of the aliphatic fractions indicated that n-alkanes were the dominant compounds present in this fractions. The distribution of n-alkanes showed the presence of low (between $\mathrm{C}_{12}-\mathrm{C}_{14}$ ) and high (between $\mathrm{C}_{22}-\mathrm{C}_{30}$ ) molecular weight compounds, with even carbon number predominance. Smooth even carbon number distributions in the range $n-C_{20}-n-C_{30}$ range have been ascribed to reductive processes or bacterial inputs (Elias et al., 1997).

Among aromatic compounds, polycyclic aromatic hydrocarbons (PAHs) and polychlorinated biphenyls (PCBs) were below the detection limit. However, di-n-butyl phthalate (DBP) and di-(2-ethyl hexyl) phthalate (DEHP) were detected. These compounds are of high environmental relevance due to its ecotoxicological potential (US.EPA, 1992). Because of their low solubility, these substances tend to precipitate from wastewater and concentrate in sludge (Abad et al., 2005). Therefore, the concentration of phthalic acid esters have to be carefully monitored in biosolids of Buenos Aires City, for it may regulate the maximum dose of land application according to National Legislation (Decreto 831/93).

\section{Conclusions}

The GC/MS analysis allowed the identification of the organic compounds present in Buenos Aires City's biosolids. Fatty acids constituted the predominant polar fraction, representing $51 \%$ of the organic compounds; whereas steroids and aliphatic compounds represented $13 \%$ and $14 \%$ respectively. Polycyclic aromatic hydrocarbons (PAHs) and polychlorinated biphenyls (PCBs) were below detection limits. However, di-n-butyl phthalate (DBP) and di-(2-ethyl hexyl) phthalate (DEHP) were detected. These latter compounds need to be carefully monitored if biosolids are land applied, and its fate in the environment requires further research. We conclude that the recalcitrant organic fraction reported in previous research may be due to the presence of stable sterols.

\section{References}

Abad, E., Martinez, K., Planas, C., Palacios, O., Caixach, J., Rivera, J. 2005. Priority organic pollutant assessment of sludges for agricultural purposes. Chemosphere, 61, 1358-1369.

Albaseer, S.S., Nageswara Rao, R., Swamy, Y.V., Mukkanti, K. 2010. An overview of sample preparation and extraction of synthetic pyrethroids from water, sediment and soil. Journal of Chromatography A 1217, 5537-555.

Codina G., Vaquero M.T., Comellas L. and F. BrotoPuig. 1994. Comparison of various extraction and clean-up methods for the determination of polycyclic aromatic hydrocarbons in sewage sludgeamended soils. Journal of Chromatography A 673, 21-29.

Decreto 831/93, Ley 24.051, Niveles guía de calidad de suelo, Tabla 9. Anexo II 
Elias, V.O., Simoneit, B.R.T., Cardoso, J.N. 1997. Even n-alkane predominances on the Amazon Shelf and a Northeast Pacific Hydrothermal System. Naturwissenschaften $84,415-420$.

EU-RAR, 2008. European Union Risk Assessment Report on Bis(2-ethylhexyl) Phthalate (DEHP). Institute of Health and Consumer Protection (IHCP), European Chemicals Bureau, 2nd Priority List, vol. 80.

Gibson, R., Wang, M.-J., Padgett, E., Beck, A.J. 2005. Analysis of 4-nonylphenols, phthalates, and polychlorinated biphenyls in soils and biosolids. Chemosphere 61, 1336-1344.

Harrison E.Z., S.R. Oakes, M. Hysell and Hay, A. 2006. Organic chemicals in sewage sludges, Science of the Total Environment 367. 481-497.

Huang, C.-C. 2008. Polyneuropathy induced by nhexane intoxication in Taiwan. Acta Neurologica Taiwanica 17, 3-10.

Huang, W., Yang, L., Liu, R., Yang, D., Wang, D. 2011. Optimization of combined ultrasound and micro-wave assisted extraction for the determination of four phthalate esters in sole materials by gas chromatography-mass spectrometry. Fresenius Environmental Bulletin 20, 793-801.

Jardé, E., Mansuy, L., Faure, P. 2005. Organic markers in the lipidic fraction of sewage sludges. Water Research 39, 1215-1232.

Kristenson, E.M., Neidig, H.C., Vreuls, R.J.J., Brinkman, U.A.Th. 2005. Fast miniaturised sample preparation for the screening and comprehensive two-dimensional gas chromatographic determination of polychlorinated biphenyls in sludge. Journal of Separation Science 28, 1121-1128.

Manoli E., Samara C. 1996. Polycyclic aromatic hydrocarbons in waste waters and sewage sludge: Extraction and clean-up for HPLC analysis with fluorescence detection Chromatographia 43, 135142.
Masih, A., Taneja, A. 2006. Polycyclic aromatic hydrocarbons (PAHs) concentrations and related carcinogenic potencies in soil at a semi-arid region of India. Chemosphere 65, 449-456.

Passuello, A., Mari, M., Nadal, M., Schuhmacher, M., Domingo, J.L. 2010. POP accumulation in the food chain: Integrated risk model for sewage sludge application in agricultural soils. Environment International 36, 577-583.

Quéméneur, M., Marty, Y. 1994. Fatty acids and sterols in domestic wastewaters, Water Research 28, 1217-1226.

Rao K. S., Dominic R., Singh K., Kaluwin C., Rivett D.E., Jones G.P. 1990. Lipid, fatty acid, and mineral composition of five edible plant leaves. Journal of Agricultural and Food Chemistry. 38, 2137-2139.

Santos, J.L., Aparicio, I., Alonso, E. 2007. A new method for the routine analysis of LAS and PAH in sewage sludge by simultaneous sonication-assisted extraction prior to liquid chromatographic determination. Analytica Chimica Acta 605, 102109.

Takada H., Eganhouse, R.P. 1998. Molecular markers of anthropogenic waste. In: R.A. Meyers (Ed.), Encyclopedia of Environmental Analysis and Remediation, Wiley, New York, pp. 2883-2940.

Torri, S., Alvarez, R., Lavado, R. 2003. Mineralization of carbon from sewage sludge in three soils of the Argentine pampas, Communications in Soil Science and Plant Analysis 34, 2035-2043.

Torri, S.I., Lavado, R.2008 a. Zinc distribution in soils amended with different kinds of sewage sludge. Journal of Environmental Management 88, 15711579.

Torri, S.I., Lavado, R.S. 2008 b. Dynamics of Cd, Cu and $\mathrm{Pb}$ added to soil through different kinds of sewage sludge, Waste Management. 28, 821-832. 
US. EPA, 1992. Code of federal regulation, 40 CFR Part 136.

Walker, R.W., Wun, C.K., Litsky, W. 1982. Coprostanol as an indicator of fecal pollution, Critical Reviews in Environmental Control, 12, 91-112.
Zhou, Q., Sang, Y., Wang, L., Ji, S., Ye, J., Wang, X. 2010. Determination of polychlorinated biphenyls by GC/MS with ultrasound-assisted extraction from shellfish. Frontiers of Agriculture in China 4, 489-493 